\title{
Electronic and Magnetic Properties Studies on Mn and Oxygen Vacancies Codoped Anatase $\mathbf{T i O}_{2}$
}

\author{
Zhongpo Zhou, ${ }^{1,2,3}$ Xinwei Yang, ${ }^{4}$ Haiying Wang, ${ }^{1,2}$ Zhaorui Zou, ${ }^{1,2}$ and Jingjing Guo ${ }^{1,2}$ \\ ${ }^{1}$ College of Physics and Material Science, Henan Normal University, Xinxiang 453007, China \\ ${ }^{2}$ Henan Key Laboratory of Photovoltaic Materials, Xinxiang 453007, China \\ ${ }^{3}$ Key Laboratory of Artificial Micro- and Nano-Structures of Ministry of Education and School of Physics and Technology, \\ Wuhan University, Wuhan 430072, China \\ ${ }^{4}$ College of Electronic and Electrical Engineering, Henan Normal University, Henan 453007, China
}

Correspondence should be addressed to Zhongpo Zhou; paul@whu.edu.cn and Haiying Wang; wanghaiy@whu.edu.cn

Received 11 June 2016; Accepted 23 August 2016

Academic Editor: Jörg Fink

Copyright ( 2016 Zhongpo Zhou et al. This is an open access article distributed under the Creative Commons Attribution License, which permits unrestricted use, distribution, and reproduction in any medium, provided the original work is properly cited.

The electronic and magnetic properties of $\mathrm{Mn}$ and oxygen vacancies codoped anatase $\mathrm{TiO}_{2}$ were investigated. The calculated results showed that the $\mathrm{TiO}_{2}$ codoped with $\mathrm{Mn}$ and oxygen vacancies have a magnetic moment value of $3.415 \mu_{\mathrm{B}}$ per $\mathrm{Ti}_{31} \mathrm{MnO}_{63}$ supercell. Furthermore, $\mathrm{Ti}_{31} \mathrm{MnO}_{63}$ gets the lowest energy with a geometrical optimization where the Mn ions locate at the nearest-neighbor sites of the oxygen vacancy. And experimental results indicated the magnetism is associated with the defects of Mn ions and oxygen vacancies induced by the Mn doping, which is consistent with the calculation results.

\section{Introduction}

Diluted magnetic semiconductors (DMSs), which are desirable for spintronic applications, have been extensively investigated for their magnetic and transport properties. Oxygen vacancies $\left(\mathrm{V}_{\mathrm{O}} \mathrm{s}\right)$ are important intrinsic defect in $\mathrm{TiO}_{2}$ which can be manipulated by oxygen gas pressure in the process of the fabrication, and they could alternate the materials' properties significantly [1-10]. The origin of the observed ferromagnetism has been considered to be related closely to the $\mathrm{V}_{\mathrm{O}} \mathrm{s}$ instead of the cation vacancies reported by Wang et al. [11]. The magnetization enlarges as $\mathrm{V}_{\mathrm{O}}$ content increases in oxygen-deficient $\mathrm{TiO}_{2}\left(\mathrm{TiO}_{2-\delta}\right)$ films observed by Yoon et al. [8]. And the carrier is n-type and the resistivity increases upon cooling [12] according to the transport measurements. Several theoretical investigations employed by first principle have been reported, most of which focus on cation vacancy in $\mathrm{TiO}_{2}$ bulk materials [13-28]. However, less attention has been drawn to the $\mathrm{V}_{\mathrm{O}}$ doped anatase $\mathrm{TiO}_{2}$ and $\mathrm{V}_{\mathrm{O}}-\mathrm{Mn}$ codoped anatase $\mathrm{TiO}_{2}$ in those researches.

There are three questions that should be figured out: (1) what is the electronic orbital composition of a $\mathrm{V}_{\mathrm{O}}$-induced state in detail for anatase $\mathrm{TiO}_{2}$ ? (2) What is the electronic orbital geometry for the $\mathrm{V}_{\mathrm{O}}-\mathrm{Mn}$ induced states in $\mathrm{V}_{\mathrm{O}}-\mathrm{Mn}$ codoped anatase $\mathrm{TiO}_{2}$ ? (3) What is the most stable structure for $\mathrm{V}_{\mathrm{O}}-\mathrm{Mn}$ codoped anatase $\mathrm{TiO}_{2}$ ? It is necessary to bring further insight into the origin of the ferromagnetism in the $\mathrm{TiO}_{2}$ with the transition-metal doping, where the $\mathrm{V}_{\mathrm{O}}$ s play an important role in promoting long-range ferromagnetic order [29]. In this paper, we investigated the electronic and magnetic properties of $\mathrm{Mn}$ and $\mathrm{V}_{\mathrm{O}} \mathrm{S}$ codoped anatase $\mathrm{TiO}_{2}$ $\left(\mathrm{Ti}_{31} \mathrm{MO}_{63}\right)$ using the first-principles method based on the density functional theory (DFT). The experimental results are consistent with that of the first principles calculations, and the magnetism is associated with the $\mathrm{V}_{\mathrm{O}}$ defect electrons induced by the Mn doping. The connections between the doped Mn ions and $\mathrm{V}_{\mathrm{O}} \mathrm{s}$ are discussed to explain the ferromagnetism observed in these materials.

\section{Experiments and Model Calculations}

The undoped $\mathrm{TiO}_{2}$ films were fabricated by sol-gel spin coating. Step one: $\mathrm{Mn}$-doped $\mathrm{TiO}_{2}$ sol-gel solution preparation. In this step, titanium isoproxide (99\%), absolute ethanol and 
hydrochloric acid were used as starting materials. Firstly, $10 \mathrm{~mL}$ titanium isoproxide was dissolved in $70 \mathrm{~mL}$ absolute ethanol solution. The mixture was stirred for $5 \mathrm{~min}$. Then $2 \mathrm{~mL}$ of $2 \mathrm{~mol} / \mathrm{L}$ hydrochloric acid was added to the mixture and was stirred for $5 \mathrm{~min}$. And then $30 \mathrm{~mL}$ absolute ethanol solution and proper weight of $\mathrm{MnCl}_{2}$ (to obtain a doping concentration of $1 \mathrm{~mol} \%, 3 \mathrm{~mol} \%, 5 \mathrm{~mol} \%, 7 \mathrm{~mol} \%$, and $9 \mathrm{~mol} \%$ resp.) were added to the mixture and then were stirred for $24 \mathrm{~h}$. Subsequently, the solution was kept stirred for $2 \mathrm{~h}$ with a heating magnetic stirrer until the sol-gel formed. Step two: the preparation of the $\mathrm{Mn}$-doped anatase $\mathrm{TiO}_{2}$ films using a spin coating method. Firstly, the fluorine-doped tin oxide (FTO) substrates were cleaned in de-ion water and in absolute ethanol solution for $5 \mathrm{~min}$ with ultrasonic cleaner, respectively. Then, the anatase $\mathrm{TiO}_{2}$ films were prepared using $\mathrm{TiO}_{2}$ sol-gel by the spin coating method. The spin rate was $400 \mathrm{rpm}$ for $10 \mathrm{~s}$ and then was extended to $3000 \mathrm{rpm}$ for $25 \mathrm{~s}$. This spin coating procedure was repeated for five times to get the ideal film thickness of $800 \mathrm{~nm}$. After coating, these samples were treated at $450^{\circ} \mathrm{C}$ in atmosphere for $2 \mathrm{~h}$ and cooled down naturally. All the reagents of acetone, absolute ethanol, titanium isoproxide, manganese dichloride, and hydrochloric acid were of analytical grade without further purification. The surface morphologies of $\mathrm{TiO}_{2}$ films were observed by the scanning electron microscopy (SEM, S-4800). X-ray photoelectron spectroscopy (XPS, VG Multilab 2000x) was utilized to qualify and the chemical compositions and identify electronic structures. The binding energy of the XPS spectra was calibrated with the reference to the $\mathrm{C} 1 \mathrm{~s}$ peak at $284.6 \mathrm{eV}$. The magnetic properties were investigated using a vibrating sample magnetometer (VSM) equipped in the physical property measurement system (PPMS-9, Quantum Design).

First-principles calculations based on spin-polarized density-functional theory and projector augmented wave (PAW) pseudopotential technique are performed as implemented within the Vienna Ab-Initio Simulation Package (VASP) [30, 31]. The generalized gradient approximation (GGA-PBE) for the wave functions is used with a cutoff of $400 \mathrm{eV}$ to model the exchange and correlation functional [32]. The calculations have been carried out for two cases: (1) an oxygen atom is substituted by a $\mathrm{V}_{\mathrm{O}}$; (2) a titanium (Ti) atom and an oxygen atom are substituted by a $\mathrm{Mn}$ atom and $\mathrm{V}_{\mathrm{O}}$. The Monkhorst-Pack scheme $k$-points grid sampling was set to be $2 \times 2 \times 5$ for the 95 -atom anatase supercell, $\mathrm{Ti}_{31} \mathrm{MnO}_{63}$ (corresponding to doping content of $\mathrm{Mn} \sim 3.13 \%)$. The valence electrons configuration for the $\mathrm{O}, \mathrm{Ti}$, and $\mathrm{Mn}$ are $2 \mathrm{~s}^{2} 2 \mathrm{p}^{4}, 3 \mathrm{~s}^{2} 3 \mathrm{p}^{6} 3 \mathrm{~d}^{2} 4 \mathrm{~s}^{2}$, and $3 \mathrm{~d}^{5} 4 \mathrm{~s}^{2}$, respectively. All the atomic positions are fully optimized until the atom forces drop below the value $0.02 \mathrm{eV} / \AA$. The DFT method has been proven to be one of the most accurate methods for the computation of the electronic structure of solids [4-7].

\section{Results and Discussions}

3.1. Electronic Properties and Magnetism of a $\mathrm{V}_{\mathrm{O}}$ Doped $\mathrm{TiO}_{2}$. According to the crystal field theory, due to the hybridization of $\mathrm{Ti}-\mathrm{O}$, the $\mathrm{Ti} 3 \mathrm{~d}$ orbits split into two parts, the $t_{2 g}\left(\mathrm{~d}_{x y}\right.$, $\left.\mathrm{d}_{x z}, \mathrm{~d}_{y z}\right)$ and $e_{g}\left(\mathrm{~d}_{z 2}, \mathrm{~d}_{x 2-y 2}\right)$ states. Geometrically, $t_{2 g}$ orbitals have lobes pointing between oxygen atoms, while $e_{g}$ orbitals point toward oxygen. The $\mathrm{O} 2 \mathrm{p}$ orbit split into $\mathrm{p}_{\pi}$ and $\mathrm{p}_{s}$ states. $\mathrm{O} 2 \mathrm{p}$ and the $t_{2 g}\left(\mathrm{~d}_{x z}, \mathrm{~d}_{y z}\right)$ of Ti $3 \mathrm{~d}$ devoted to the valence band ( $\mathrm{p}_{\pi}$ devote to the top of valance band), while the conduction band was contributed by the $\mathrm{d}_{x y}$ and $e_{g}$ of $\mathrm{Ti}$ $3 \mathrm{~d}\left(\mathrm{~d}_{x y}\right.$ devotes to the bottom of conduction band) [33]. In the ionic limit, each Ti gives four electrons to two oxygen atoms, resulting in the nominal charges of $\mathrm{Ti}^{4+}$ and $\mathrm{O}^{2-}$ [12]. When the $\mathrm{V}_{\mathrm{O}}$ is introduced into the lattice, each $\mathrm{V}_{\mathrm{O}}$ is assumed to donate two electrons. For Figure 1(b) (I), the TDOS of $\mathrm{V}_{\mathrm{O}^{-}}$ doped anatase $\mathrm{TiO}_{2}$, there is a spin-split lower around the Fermi level illustrating the existence of magnetism. Such a state is stabilized in the spin-polarized DFT calculation (with a lower free energy of $0.0042 \mathrm{eV}$ than the result of nonspin-polarized DFT calculation). The calculated net magnetic moment is about $0.533 \mu_{\mathrm{B}}$. Figure 1(a) (II, III, and IV) shows the orbital decomposed density of states for three $\mathrm{Ti} 3 \mathrm{~d}$ electrons nearest to the $\mathrm{V}_{\mathrm{O}}$. Three $\mathrm{Ti}$ atoms are labeled as $\mathrm{Ti}$ II, Ti-III, and Ti-IV, with Ti-III and Ti-IV being equivalent with respect to the vacancy. It can be seen from the figure that, for Ti-II atom, the exchange spin-splitting at the bottom of the conduction band is mainly derived from the one $e_{g}$ orbital $\left(\mathrm{d}_{x y}\right)$ and two $t_{2 g}$ orbitals $\left(\mathrm{d}_{y z}\right.$ and $\left.\mathrm{d}_{x 2}\right)$, while the exchange spin-splitting at the bottom of the conduction band is mainly derived from the one $e_{g}$ orbital $\left(\mathrm{d}_{z 2}\right)$ and two $t_{2 g}$ orbitals $\left(\mathrm{d}_{y z}\right.$ and $\left.\mathrm{d}_{x 2}\right)$ for Ti-II and Ti-IV atom. The orbitals overlap between the three Ti atoms nearest to the $\mathrm{V}_{\mathrm{O}}$. The hybridization between these three $\mathrm{Ti} 3 \mathrm{~d}$ electron states leads to the electrons of $\mathrm{Ti} 3 \mathrm{~d}$ spin-polarized. The charge distribution is illustrated in Figure 1(b). It can be seen that the state spread over all three Ti atoms adjacent to the vacancy and the local orbitals are the mixture of $e_{g}$ and $t_{2 g}$ The charge distribution is similar to the charge distribution of the hybrid state in [12]. In the calculations, the results are obtained in a $\mathrm{Ti}_{32} \mathrm{O}_{63}$ anatase supercell with lowest total free energy for different $\mathrm{V}_{\mathrm{O}}$ sites. The two electrons donated by one $\mathrm{V}_{\mathrm{O}}$ are shared by the three $\mathrm{Ti}$ ions with up-spin forming $\mathrm{Ti}^{3+}$ ion to get the lowest energy. It is guessed that the appearance of the net magnetic moment in anatase $\mathrm{TiO}_{2}$ may come from the larger crystal lattice distortion compared to rutile $\mathrm{TiO}_{2}$.

3.2. Electronic Properties and Magnetism of $V_{O^{-}}-M n$ Codoped $\mathrm{TiO}_{2}$. Magnetic properties of $\mathrm{Ti}_{31} \mathrm{MnO}_{63}$ were investigated using the first-principles methods based on the DFT. The lowest energies are achieved after geometrical optimization of $\mathrm{Ti}_{31} \mathrm{MnO}_{63}$ for each $\mathrm{V}_{\mathrm{O}}$-Mn codoping models, where doped $\mathrm{Mn}$ ions are located at the nearest-neighbor site of $\mathrm{V}_{\mathrm{O}}$. The result is similar to that of the report done recently [34].

In order to understand the nature of ferromagnetism, the electronic properties and magnetism of $\mathrm{V}_{\mathrm{O}}-\mathrm{Mn}$ codoped $\mathrm{TiO}_{2}$ are investigated in detail. The lowest energy is obtained in the spin-polarized DFT calculation. Figure 2 shows the spin-resolved total density of states for the $\mathrm{Ti}_{31} \mathrm{MnO}_{63}$. The calculations show ferromagnetism with clear majority-spin defect states localized in the band gap for $\mathrm{V}_{\mathrm{O}}-\mathrm{Mn}$ codoped $\mathrm{TiO}_{2}$. The major magnetic moment originates from the $\mathrm{d}$ electron of $\mathrm{Mn}$ ions. For $\mathrm{V}_{\mathrm{O}}-\mathrm{Mn}$ codoped $\mathrm{TiO}_{2}$, the valence electrons configuration of doped $\mathrm{Mn}$ atom is $3 \mathrm{~d}^{5}$. And the 


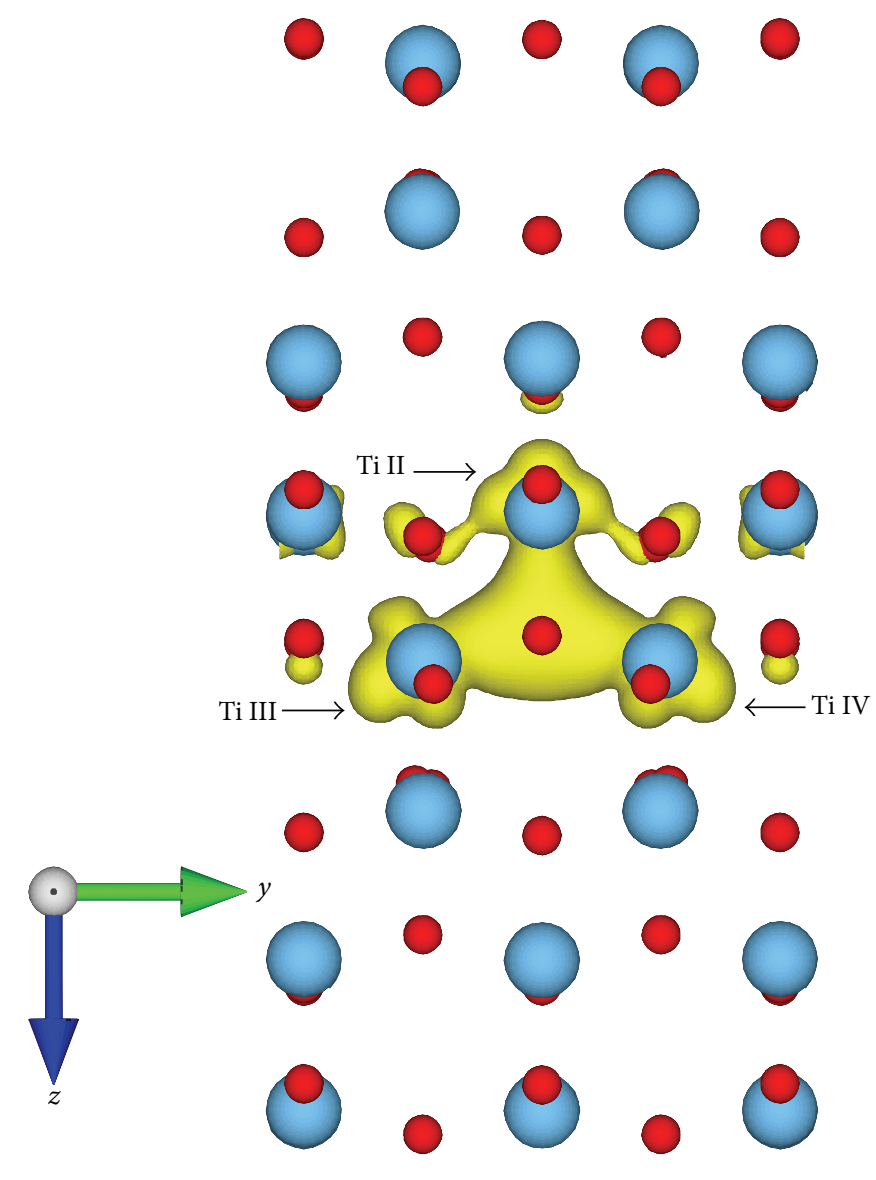

(a)

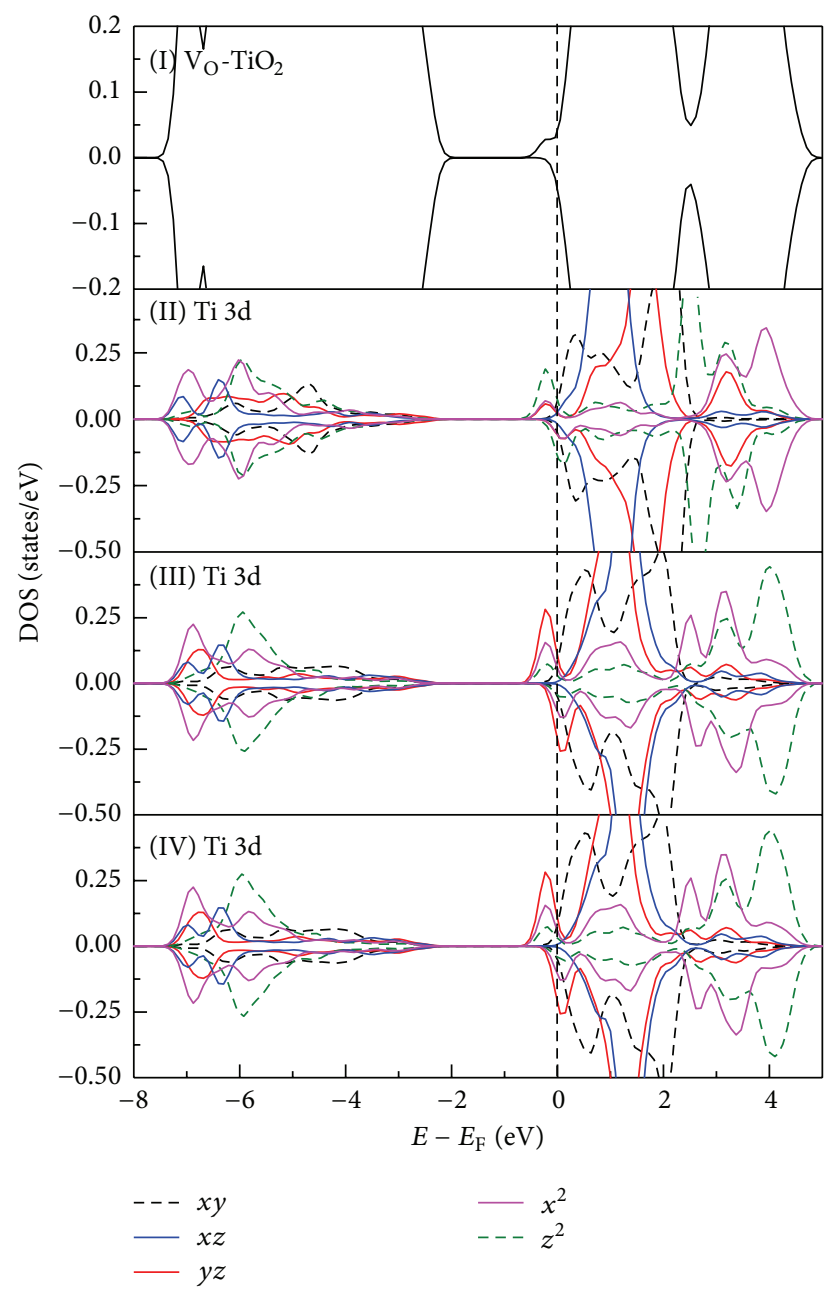

(b)

Figure 1: (a) Charge distribution of $\mathrm{V}_{\mathrm{O}}$-doped anatase $\mathrm{TiO}_{2}$. (b) $\mathrm{TDOS}$ of $\mathrm{V}_{\mathrm{O}}-\mathrm{TiO}_{2}$ and the orbitally decomposed density of states for three Ti $3 \mathrm{~d}$ electrons nearest to $\mathrm{V}_{\mathrm{O}}$. The olive and black dashed curves represent the $e_{g}$ bands; the red, blue, and magenta solid curves represent the $t_{2 g}$ bands, respectively.

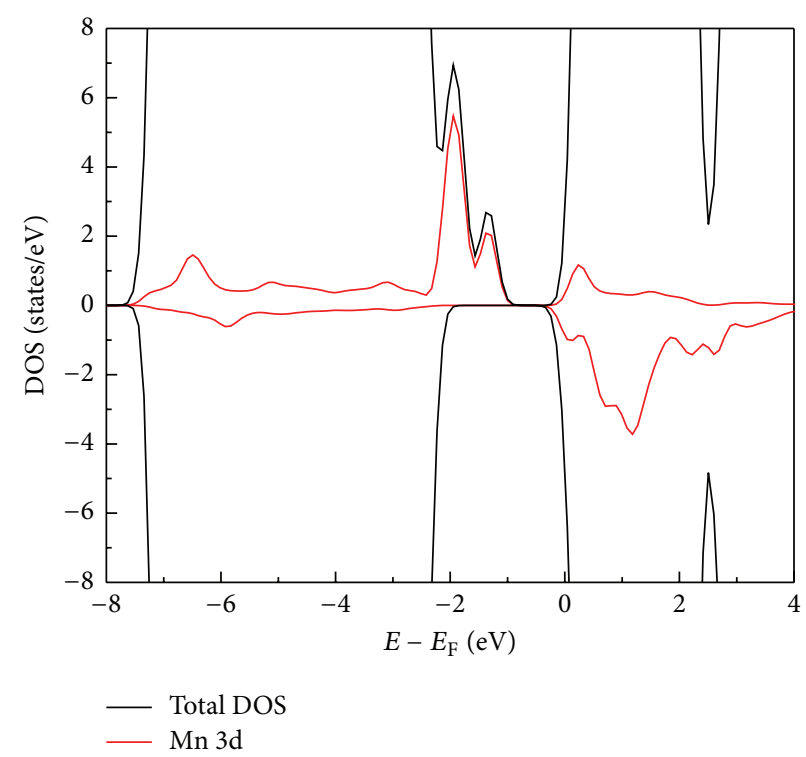

FIGURE 2: Spin-resolved total density of states for the $\mathrm{Mn}$ codoped $\mathrm{TiO}_{2}$ in combination with an oxygen vacancy and spin-and orbital-resolved PDOS for the doped Mn atom. 


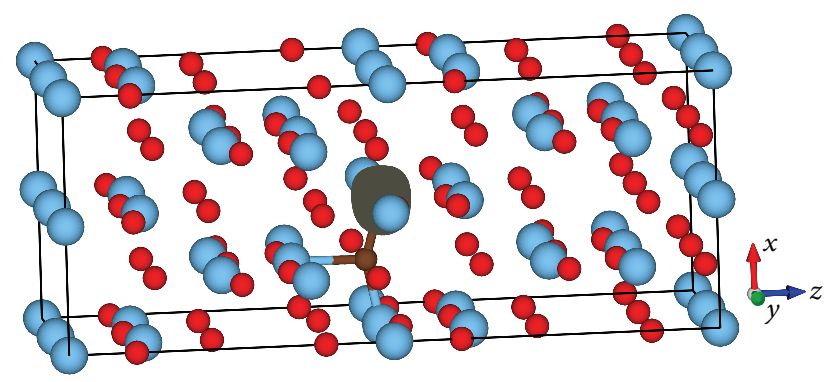

- $\mathrm{v}_{\mathrm{O}} \mathrm{T} \mathrm{Ti}$

- $\mathrm{Mn}$

(a)

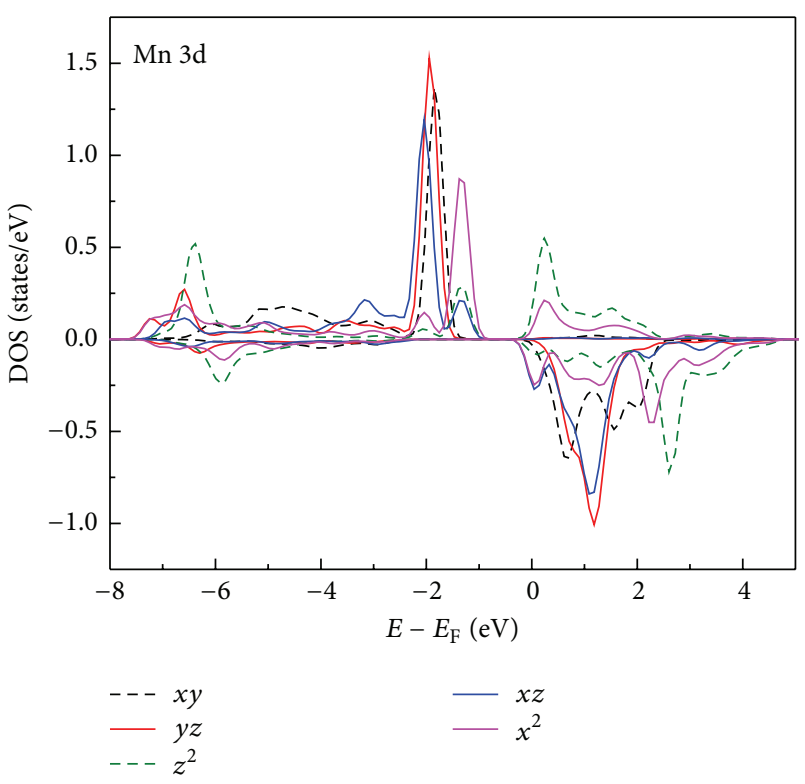

(b)

FIGURE 3: Isosurface plot of magnetization density (majority-spin minus minority-spin) for (a) $\mathrm{Ti}_{31} \mathrm{MnO}_{63}$ supercell; (b) the orbitally decomposed density of states projected on $\mathrm{Mn}$ ion.

calculated net magnetic moment is about $3.415 \mu_{\mathrm{B}}$, which is mainly contributed by doped $\mathrm{Mn}$ ion (calculated net magnetic moment is about $3.323 \mu_{\mathrm{B}}$ ).

The isosurface plot of magnetization density (majorityspin minus minority-spin) for $\mathrm{Ti}_{31} \mathrm{MnO}_{63}$ supercell and the orbital decomposed density of states projected on $\mathrm{Mn}$ ion are shown in Figure 3. Spin density distribution of $\mathrm{Ti}_{31} \mathrm{MnO}_{63}$ supercell is shown in Figure 3(a). It can be noticed that the spin densities are mainly distributed on the doped $\mathrm{Mn}$ ion. It holds the spin with up direction. The values of calculated band lengths for $\mathrm{V}_{\mathrm{O}^{-}} \mathrm{Mn}, \mathrm{V}_{\mathrm{O}^{-}}-\mathrm{Ti}$ (III), and $\mathrm{V}_{\mathrm{O}^{-}}$ Ti (IV) are $1.8073 \AA, 2.09822 \AA$, and $2.16686 \AA$, respectively. The lowest energy is achieved after geometrical optimization of $\mathrm{Ti}_{31} \mathrm{MnO}_{63}$, where one $\mathrm{Mn}$ ion is located at the nearestneighbor site of $\mathrm{V}_{\mathrm{O}}$.

The orbital decomposed density of states projected on $\mathrm{Mn}$ ion is presented in Figure 3(b). There is a complete exchange spin-splitting of Mn 3d appearing within the Fermi level.

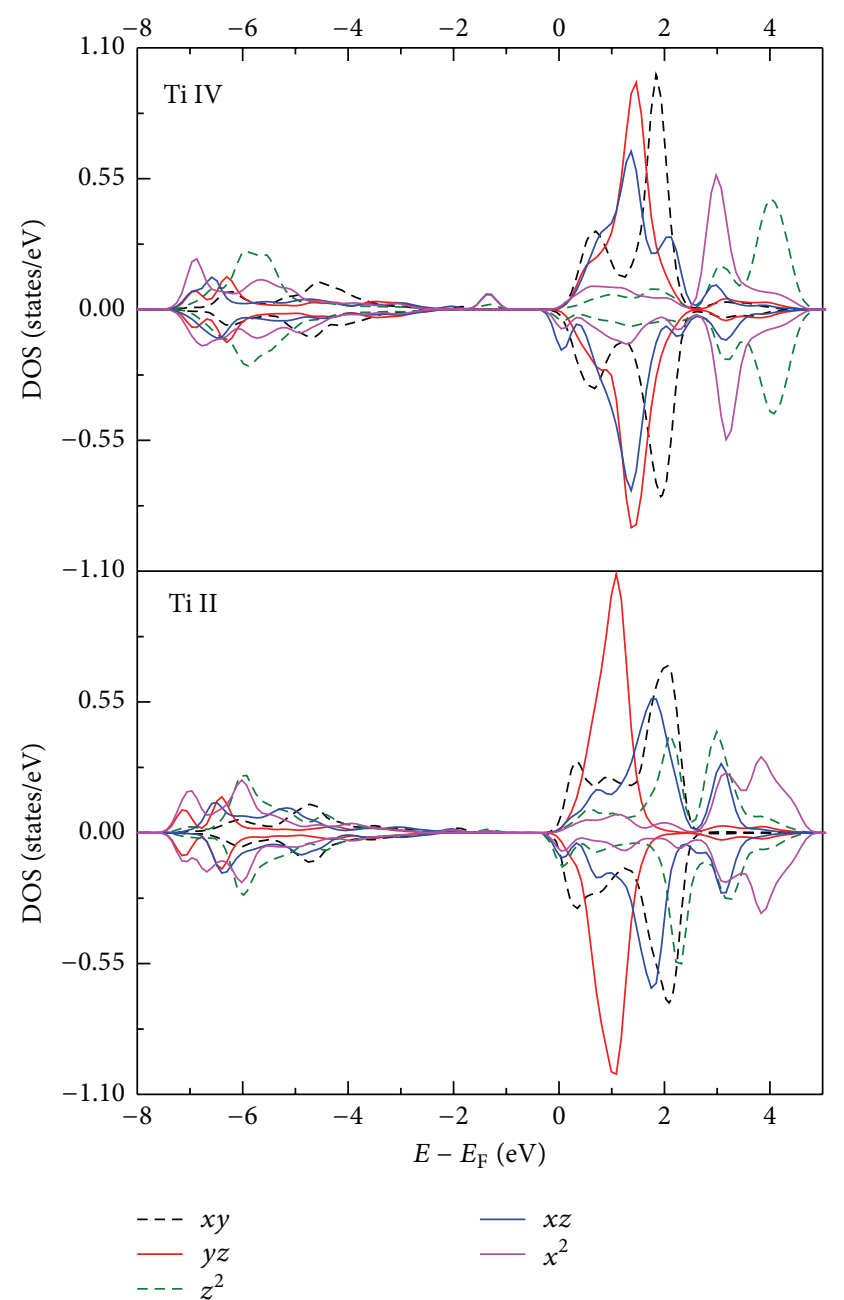

FIGURE 4: The orbital decomposed density of states projected on $\mathrm{Ti}$ II $3 \mathrm{~d}$ electrons and Ti IV $3 \mathrm{~d}$ electrons nearest to $\mathrm{V}_{\mathrm{O}}$ for $\mathrm{Ti}_{31} \mathrm{MnO}_{63}$ supercell.

The results indicate that there are $t_{2 g}$ and $e_{g}$ states of Mn $3 \mathrm{~d}$ electrons with up spin within the Fermi level. The valence electrons configuration on the $\mathrm{Mn}$ is $3 \mathrm{~s}^{2} 3 \mathrm{p}^{6} 3 \mathrm{~d}^{5}$. The orbital decomposed density of states projected on Ti II $3 \mathrm{~d}$ electrons and Ti IV 3d electrons nearest to $\mathrm{V}_{\mathrm{O}}$ for (a) $\mathrm{Ti}_{31} \mathrm{MnO}_{63}$ supercell is noticed in Figure 4. As it can be seen, there is almost no spin-splitting of Ti II $3 \mathrm{~d}$ electrons and Ti IV 3d electrons nearest to $V_{O}$ within the Fermi level. The results indicate that there are no electron states of $\mathrm{Ti} 3 \mathrm{~d}$ electrons appearing within the Fermi level, which is consistent with the result of Figure 3. That just says that, due to the difference in the electronegativity and valence between $\mathrm{Ti}^{4+}$ ion and $\mathrm{Mn}^{2+}$ ions, the effect of the substitution is that no electron is donated to the $\mathrm{TiO}_{2}$ lattice instead of two. Two electrons denoted by one $\mathrm{V}_{\mathrm{O}}$ are captured by doped $\mathrm{Mn}$ ion and two electrons donated by the doped $\mathrm{Mn}^{2+}$ ion will be captured by five $\mathrm{O}$ ions nearest. As a result, the total net magnetic moment of $\mathrm{V}_{\mathrm{O}}-\mathrm{Mn}$ codoped $\mathrm{TiO}_{2}$ is $3.415 \mu_{\mathrm{B}}$. 

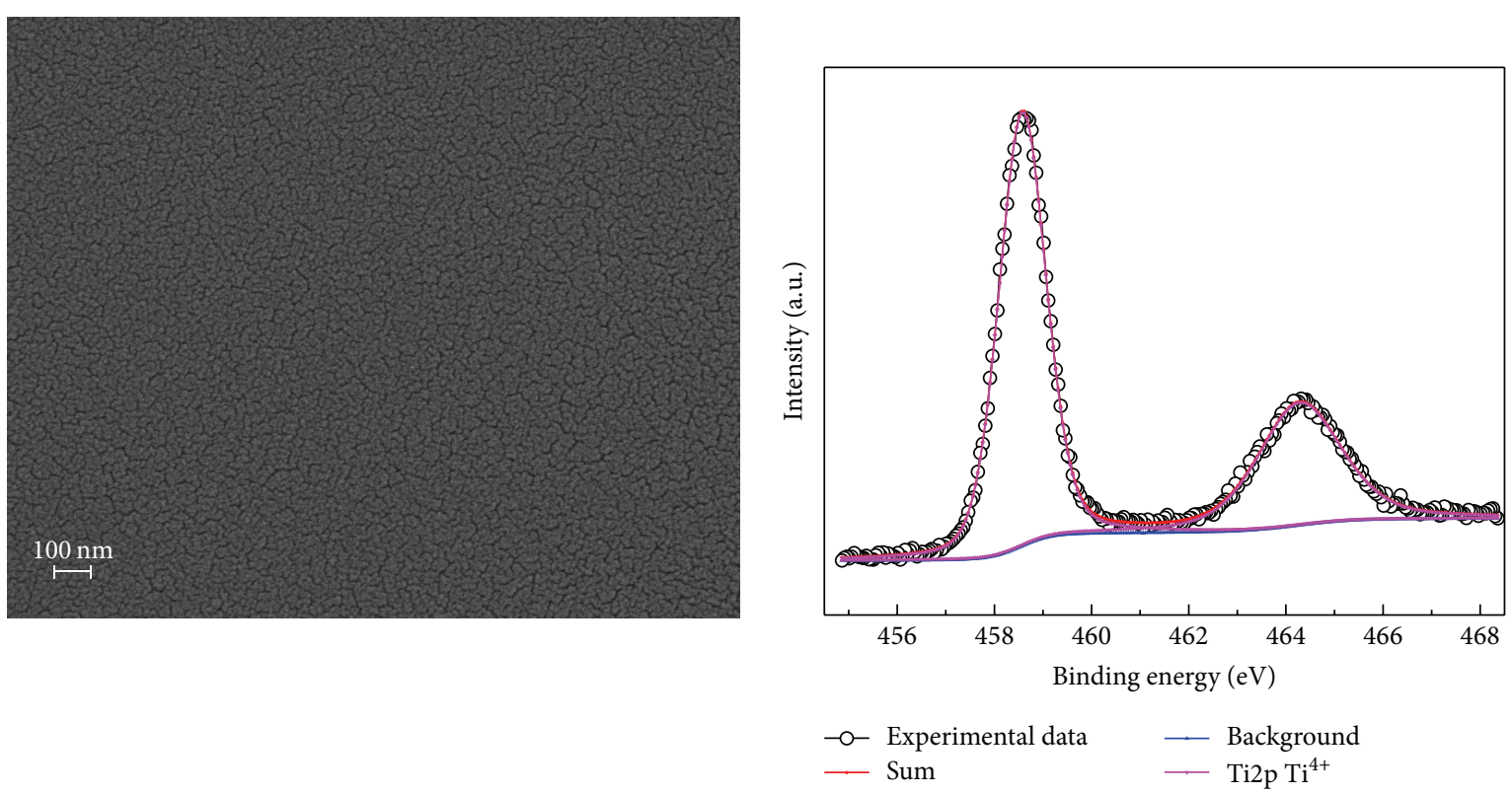

(a)

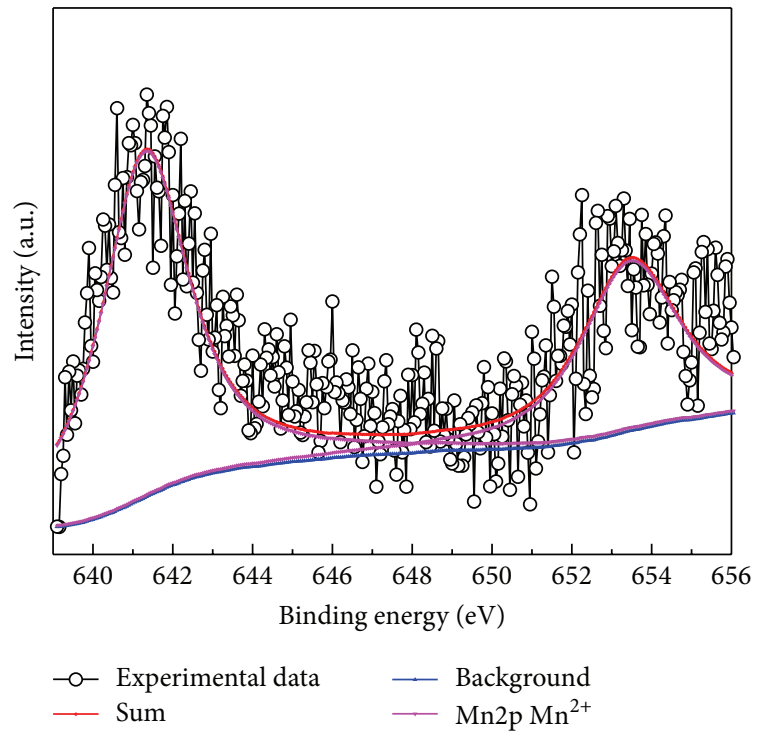

(c)

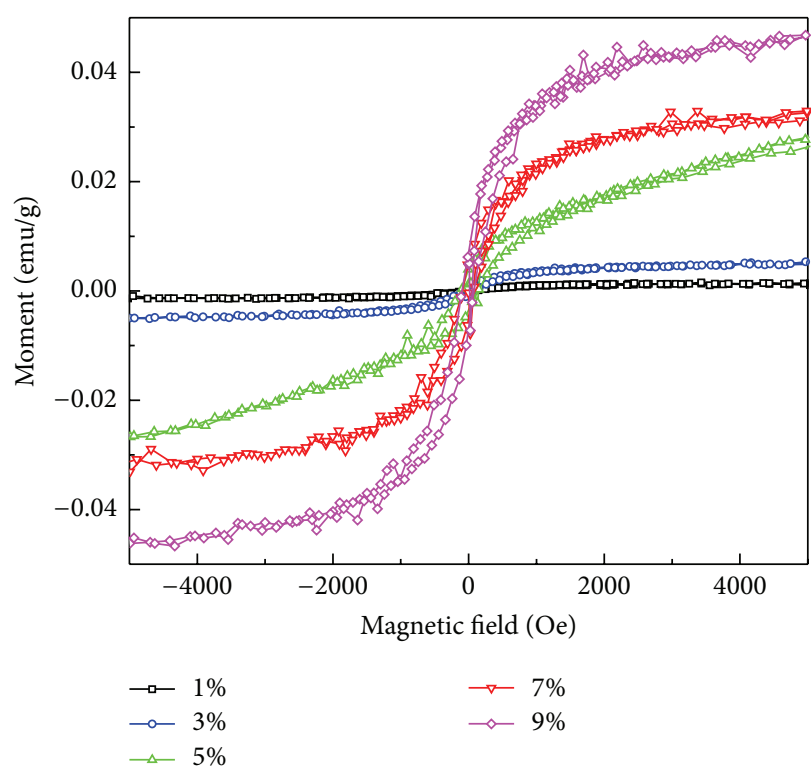

(d)

FIgure 5: (a) SEM image of $\mathrm{Ti}_{0.97} \mathrm{Mn}_{0.03} \mathrm{O}_{2}$ film; (b) XPS spectra of the core-level signal of Ti-2p and (c) Mn-2p of Ti ${ }_{0.97} \mathrm{Mn}_{0.03} \mathrm{O}_{2}$ film; (d) magnetic hysteresis curves of the $\mathrm{Mn}$-doped $\mathrm{TiO}_{2}$ films with $1 \%, 3 \%, 5 \%, 7 \%$, and $9 \%$ doping content measured at $300 \mathrm{~K}$.

3.3. Experiment Results. The calculation results are confirmed by experimental data obtained for Mn-doped $\mathrm{TiO}_{2}$ films. The $\mathrm{Mn}$-doped $\mathrm{TiO}_{2}$ films (with $1 \%, 3 \%, 5 \%, 7 \%$, and 9\% doping content) were grown by prepared by sol-gel spin coating. Figure 5(a) demonstrates the SEM images of the sample, which suggests that the film is smooth and the size of particles is about $10 \mathrm{~nm}$.

The binding state of $\mathrm{Ti}$ and $\mathrm{Co}$ in the as-synthesized cobalt incorporated $\mathrm{TiO}_{2}$ is analyzed with XPS. XPS analysis is performed after sputtering with $\mathrm{Ar}^{+}$. The $\mathrm{Ti}-2 \mathrm{p}$ and $\mathrm{Co}-$ $2 p$ core levels spectra of the $\mathrm{Ti}_{0.97} \mathrm{Mn}_{0.03} \mathrm{O}_{2}$ doped sample are shown in Figures 5(b) and 5(c). Figure 5(b) displays the Ti$2 p$ core level XPS spectrum for $\mathrm{Ti}_{0.97} \mathrm{Al}_{0.03} \mathrm{O}_{2}$ film sample. The open circles are the experimental data, the blue line is the background, the red line is the sum, and the peaks related to $\mathrm{Ti}^{4+}$ are fitted with magenta lines, where $\mathrm{Ti} 2 \mathrm{p} 3 / 2$ core level spectrum was fitted with combined GaussianLorentzian functions. The main peak of $\mathrm{Ti} 2 \mathrm{p}^{3 / 2}$ situates around at $458.5 \mathrm{eV}$ and a low intensity minor peak at $464.2 \mathrm{eV}$ is attributed to $\mathrm{Ti} 2 \mathrm{p}^{1 / 2}$, close to the binding energies of the core-level of $\mathrm{Ti}^{4+}$ ion, which indicates the existence of $\mathrm{Ti}^{4+}$. No signal of $\mathrm{Ti}^{3+}$ was detected. The $\mathrm{Ti}^{3+}$ ions were also not 
observed in other Mn-doped films, which is not like the case of $\mathrm{Nb}$ - or Fe-doped $\mathrm{TiO}_{2}$ films, due to the difference in the electronegativity and valence between $\mathrm{Mn}$ ion, $\mathrm{Nb}$ ion, and $\mathrm{Fe}$ ion $[35,36]$. Figure 5(c) shows the $\mathrm{Mn}-2 \mathrm{p}$ core-level XPS spectrum for $\mathrm{Ti}_{0.97} \mathrm{Mo}_{0.03} \mathrm{O}_{2}$ films. The open circles are the experimental data, the blue line is the background, the red line is the sum, and the peaks related to $\mathrm{Mn}^{2+}$ ion are fitted with magenta lines. The main peak of $\mathrm{Mn} 2 \mathrm{p}^{3 / 2}$ situates around at $641.2 \mathrm{eV}$ and a low intensity minor peak at $653.6 \mathrm{eV}$ is attributed to $\mathrm{Mn} 2 \mathrm{p}^{1 / 2}$, respectively, close to the binding energies of the core level of $\mathrm{Mn}^{2+}$ ion and lower to the binding energies of the core-levels of $\mathrm{Mn}^{3+}$ ion and $\mathrm{Mn}^{4+}$ ion, which indicates the existence of $\mathrm{Mn}^{2+}$.

Figure 5(d) indicates the magnetic hysteresis (M-H) curves of Mn-doped samples (with $1 \%, 3 \%, 5 \%, 7 \%$, and 9\% doping content) at room temperature. All the Mn-doped samples showed ferromagnetism at room temperature (RT). The saturation magnetization $\mathrm{M}_{S}$ increases rapidly as the $\mathrm{Mn}$ content increases from $1 \%$ to $9 \%$, alike other reports [37]. The magnetic moment per doped Mn atom exhibits more or less constant values for the $1 \%$ to $9 \%$ samples, up to the present experimental data.

Combining the calculation and experimental results presented above, we introduce a defect electron based model for the observed ferromagnetism. The magnetic moment associated with a $\mathrm{Mn}^{2+} / \mathrm{V}_{\mathrm{O}} / \mathrm{Ti}^{4+}$ complex is spread over two or more neighboring Ti sites. These moments are aligned ferromagnetic. The major contribution to the magnetic moment of our $\mathrm{Mn}$-doped $\mathrm{TiO}_{2}$ films comes from the unpaired d electron of $\mathrm{Mn}^{2+}$, consistent with our first-principles calculation.

\section{Conclusions}

Electronic and magnetic properties of $\mathrm{Ti}_{31} \mathrm{MnO}_{63}$ have been studied combined with experiments and the first-principles calculations. Magnetic moment value is $3.415 \mu_{\mathrm{B}}$ per supercell for the $\mathrm{V}_{\mathrm{O}}-\mathrm{Mn}$ codoped anatase $\mathrm{TiO}_{2}$. The lowest energy is achieved after geometrical optimization of $\mathrm{Ti}_{31} \mathrm{MnO}_{63}$, where doped $\mathrm{Mn}$ atoms are located at the nearest-neighbor site of $\mathrm{V}_{\mathrm{O}}$. Four electrons donated by the the $\mathrm{V}_{\mathrm{O}}$ doped $\mathrm{Mn}^{2+}$ ion are shared by the nearest five $\mathrm{O}$ ions. The major magnetic moment originates from the delectron of Mn. Ferromagnetic behavior in $\mathrm{V}_{\mathrm{O}}-\mathrm{Mn}$ doped $\mathrm{TiO}_{2}$ is corresponding to the strong $\mathrm{Mn} \mathrm{d}$-shell contribution and $\mathrm{V}_{\mathrm{O}}$. The calculation results are confirmed by experimental data of $\mathrm{Mn}$-doped $\mathrm{TiO}_{2}$ films.

\section{Competing Interests}

The authors declare that there is no conflict of interests regarding the publication of this paper.

\section{Acknowledgments}

This work is supported by the NSFC nos. 11404100, 11175135, 10904116, and 11304083, the Post-Doctoral Research Foundation of Henan Province no. 01026500204, and the Scientific
Research Foundation for PhD of Henan Normal University nos. 01026500257 and 01026500121 . This work is also supported by the High Performance Computing Center of Henan Normal University.

\section{References}

[1] A. Fujishima and K. Honda, "Electrochemical photolysis of water at a semiconductor electrode," Nature, vol. 238, no. 5358, pp. 37-38, 1972.

[2] J. T. Yates Jr., "Photochemistry on $\mathrm{TiO}_{2}$ : mechanisms behind the surface chemistry," Surface Science, vol. 603, no. 10-12, pp. 16051612, 2009.

[3] B. Li, J. Zhao, K. Onda, K. D. Jordan, J. Yang, and H. Petek, "Ultrafast interfacial proton-coupled electron transfer," Science, vol. 311, no. 5766, pp. 1436-1440, 2006.

[4] M. Ramamoorthy, R. D. King-Smith, and D. Vanderbilt, "Defects on $\mathrm{TiO}_{2}$ (110) surfaces," Physical Review B, vol. 49, no. 11, pp. 7709-7715, 1994.

[5] C. Di Valentin, G. Pacchioni, and A. Selloni, "Electronic structure of defect states in hydroxylated and reduced rutile $\mathrm{TiO}_{2}$ (110) surfaces," Physical Review Letters, vol. 97, no. 16, Article ID 166803, 2006.

[6] U. Diebold, "The surface science of titanium dioxide," Surface Science Reports, vol. 48, no. 5-8, pp. 53-229, 2003.

[7] J. H. Lee and A. Selloni, “ $\mathrm{TiO}_{2}$ /ferroelectric heterostructures as dynamic polarization-promoted catalysts for photochemical and electrochemical oxidation of water," Physical Review Letters, vol. 112, no. 19, Article ID 196102, 2014.

[8] S. D. Yoon, Y. Chen, A. Yang et al., "Oxygen-defect-induced magnetism to $880 \mathrm{~K}$ in semiconducting anatase $\mathrm{TiO}_{2-\delta}$ films," Journal of Physics: Condensed Matter, vol. 18, no. 27, pp. L355L361, 2006.

[9] R. K. Singhal, S. Kumar, P. Kumari, Y. T. Xing, and E. Saitovitch, "Evidence of defect-induced ferromagnetism and its 'switch' action in pristine bulk $\mathrm{TiO}_{2}$," Applied Physics Letters, vol. 98, no. 9, Article ID 092510, 2011.

[10] S. Zhou, E. Čižmár, K. Potzger et al., "Origin of magnetic moments in defective $\mathrm{TiO}_{2}$ single crystals," Physical Review BCondensed Matter and Materials Physics, vol. 79, no. 11, Article ID 113201, 2009.

[11] M. Wang, M. Feng, and X. Zuo, "First principles study of the electronic structure and magnetism of oxygen-deficient anatase $\mathrm{TiO}_{2}\left(\begin{array}{ll}0 & 0\end{array}\right)$ surface," Applied Surface Science, vol. 292, pp. 475479, 2014.

[12] C. Lin, D. Shin, and A. A. Demkov, "Localized states induced by an oxygen vacancy in rutile $\mathrm{TiO}_{2}$," Journal of Applied Physics, vol. 117, no. 22, Article ID 225703, 2015.

[13] Y. Bai and Q. Chen, "First principle study of the cation vacancy in anatase $\mathrm{TiO}_{2}$," Physica Status Solidi-Rapid Research Letters, vol. 2, no. 1, pp. 25-27, 2008.

[14] H. Peng, J. Li, S.-S. Li, and J.-B. Xia, "Possible origin of ferromagnetism in undoped anatase $\mathrm{TiO}_{2}$," Physical Review B, vol. 79, no. 9, Article ID 092411, 2009.

[15] J. Chen, L.-B. Lin, and F.-Q. Jing, "Theoretical study of F-type color center in rutile $\mathrm{TiO}_{2}$," Journal of Physics and Chemistry of Solids, vol. 62, no. 7, pp. 1257-1262, 2001.

[16] B. J. Morgan and G. W. Watson, "A density functional theory + U study of oxygen vacancy formation at the (110), (100), (101), and (001) surfaces of rutile $\mathrm{TiO}_{2}$," The Journal of Physical Chemistry C, vol. 113, no. 17, pp. 7322-7328, 2009. 
[17] N. Yu and J. W. Halley, "Electronic structure of point defects in rutile $\mathrm{TiO}_{2}$," Physical Review B, vol. 51, no. 8, pp. 4768-4776, 1995.

[18] E. Cho, S. Han, H.-S. Ahn, K.-R. Lee, S. K. Kim, and C. S. Hwang, "First-principles study of point defects in rutile $\mathrm{TiO}_{2-x}$," Physical Review B, vol. 73, no. 19, Article ID 193202, 4 pages, 2006.

[19] M. M. Islam, T. Bredow, and A. Gerson, "Electronic properties of oxygen-deficient and aluminum-doped rutile $\mathrm{TiO}_{2}$ from first principles," Physical Review B, vol. 76, no. 4, Article ID 045217, 2007.

[20] K. Yang, Y. Dai, B. Huang, and Y. P. Feng, "Density-functional characterization of antiferromagnetism in oxygen-deficient anatase and rutile $\mathrm{TiO}_{2}$," Physical Review B, vol. 81, no. 3, Article ID 033202, 2010.

[21] A. Janotti, J. B. Varley, P. Rinke, N. Umezawa, G. Kresse, and C. G. Van de Walle, "Hybrid functional studies of the oxygen vacancy in $\mathrm{TiO}_{2}$," Physical Review B, vol. 81, no. 8, Article ID 085212, 7 pages, 2010.

[22] S.-G. Park, B. Magyari-Köpe, and Y. Nishi, "Electronic correlation effects in reduced rutile $\mathrm{TiO}_{2}$ within the $\mathrm{LDA}+\mathrm{U}$ method," Physical Review B, vol. 82, no. 11, Article ID 115109, 2010.

[23] E. Finazzi, C. Di Valentin, G. Pacchioni, and A. Selloni, "Excess electron states in reduced bulk anatase $\mathrm{TiO}_{2}$ : comparison of standard GGA, GGA $+\mathrm{U}$, and hybrid DFT calculations," The Journal of Chemical Physics, vol. 129, no. 15, Article ID 154113, 2008.

[24] G. Mattioli, P. Alippi, F. Filippone, R. Caminiti, and A. Amore Bonapasta, "Deep versus shallow behavior of intrinsic defects in rutile and anatase $\mathrm{TiO}_{2}$ polymorphs," Journal of Physical Chemistry C, vol. 114, no. 49, pp. 21694-21704, 2010.

[25] A. Janotti, C. Franchini, J. B. Varley, G. Kresse, and C. G. Van de Walle, "Dual behavior of excess electrons in rutile $\mathrm{TiO}_{2}$," Physica Status Solidi-Rapid Research Letters, vol. 7, no. 3, pp. 199-203, 2013.

[26] P. Deák, B. Aradi, and T. Frauenheim, "Quantitative theory of the oxygen vacancy and carrier self-trapping in bulk $\mathrm{TiO}_{2}$," Physical Review B, vol. 86, no. 19, Article ID 195206, 2012.

[27] A. Malashevich, M. Jain, and S. G. Louie, "First-principles $\mathrm{DFT}+\mathrm{GW}$ study of oxygen vacancies in rutile $\mathrm{TiO}_{2}$," Physical Review B, vol. 89, no. 7, Article ID 075205, 2014.

[28] M. Setvin, C. Franchini, X. Hao et al., "Direct view at excess electrons in $\mathrm{TiO}_{2}$ rutile and anatase," Physical Review Letters, vol. 113, no. 8, Article ID 086402, 2014.

[29] L. C. J. Pereira, M. R. Nunes, O. C. Monteiro, and A. J. Silvestre, "Magnetic properties of Co-doped $\mathrm{TiO}_{2}$ anatase nanopowders," Applied Physics Letters, vol. 93, no. 22, Article ID 222502, 2008.

[30] G. Kresse and D. Joubert, "From ultrasoft pseudopotentials to the projector augmented-wave method," Physical Review B, vol. 59, no. 3, pp. 1758-1775, 1999.

[31] G. Kresse and J. Furthmüller, "Efficient iterative schemes for $a b$ initio total-energy calculations using a plane-wave basis set," Physical Review B, vol. 54, no. 16, pp. 11169-11186, 1996.

[32] J. P. Perdew, K. Burke, and M. Ernzerhof, "Generalized gradient approximation made simple," Physical Review Letters, vol. 77, no. 18 , pp. 3865-3868, 1996.

[33] Q. L. Chen, B. Li, G. Zheng, K. H. He, and A. S. Zheng, "Firstprinciples calculations on electronic structures of Fe-vacancycodoped $\mathrm{TiO}_{2}$ anatase (101) surface," Physica B, vol. 406, no. 20, pp. 3841-3846, 2011.
[34] X. J. Wang, Y. L. Song, L. L. Tao et al., "Origin of ferromagnetism in aluminum-doped $\mathrm{TiO}_{2}$ thin films: theory and experiments," Applied Physics Letters, vol. 105, no. 26, Article ID 262402, 2014.

[35] K. Bapna, R. J. Choudhary, S. K. Pandey, D. M. Phase, S. K. Sharma, and M. Knobel, "Electronic depiction of magnetic origin in undoped and $\mathrm{Fe}$ doped $\mathrm{TiO}_{2-\mathrm{d}}$ epitaxial thin films," Applied Physics Letters, vol. 99, no. 11, Article ID 112502, 2011.

[36] J. Y. Yang, Y. L. Han, L. He, R. F. Dou, C. M. Xiong, and J. C. Nie, "d carrier induced intrinsic room temperature ferromagnetism in $\mathrm{Nb}: \mathrm{TiO}_{2}$ film," Applied Physics Letters, vol. 100, no. 20, Article ID 202409, 2012.

[37] A. Manivannan, M. S. Seehra, S. B. Majumder, and R. S. Katiyar, "Magnetism of Co-doped titania thin films prepared by spray pyrolysis," Applied Physics Letters, vol. 83, no. 1, pp. 111-113, 2003. 

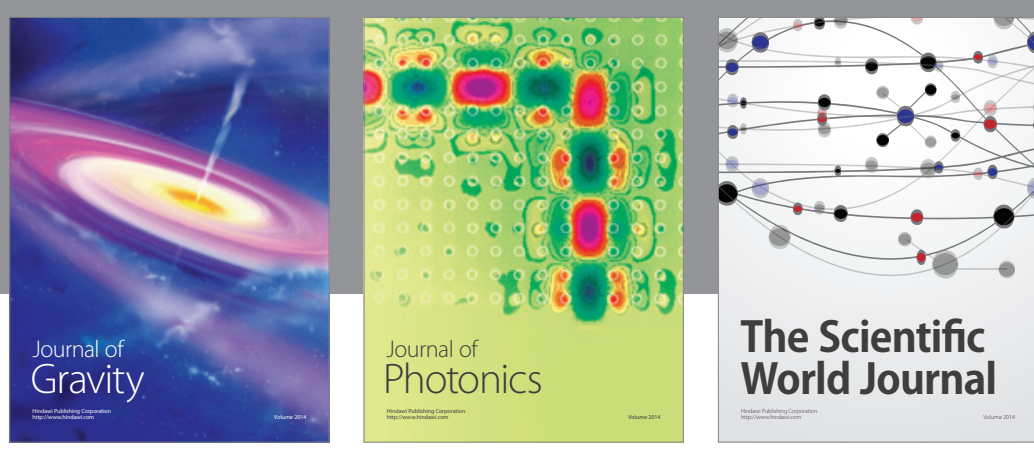

The Scientific World Journal
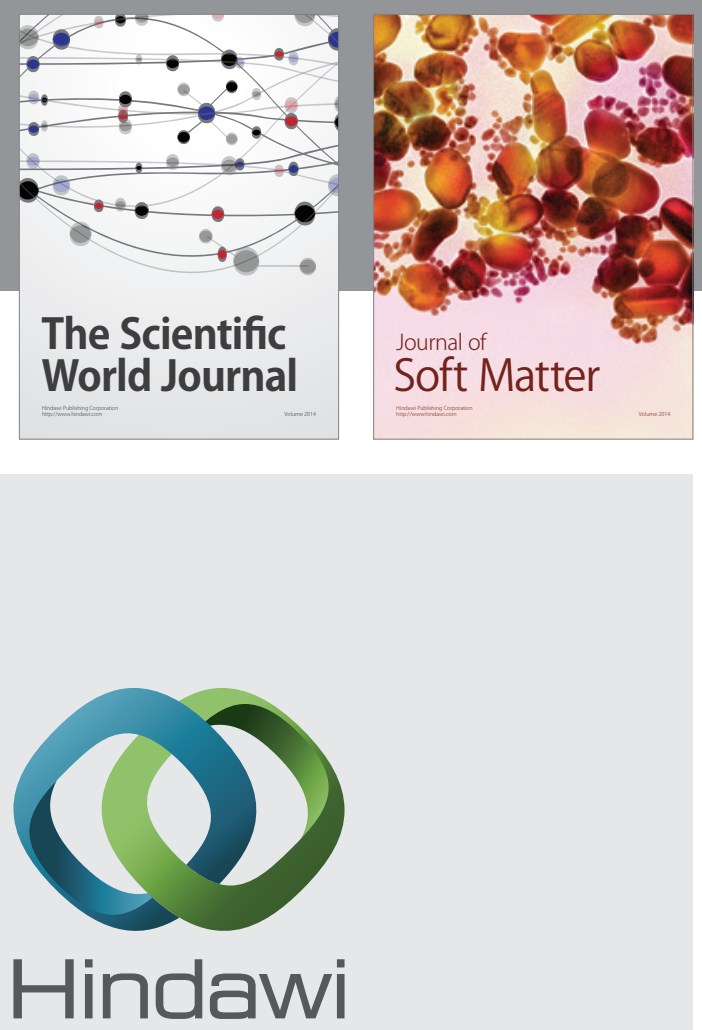

Submit your manuscripts at

http://www.hindawi.com

nternational Journal of

Statistical Mechanics
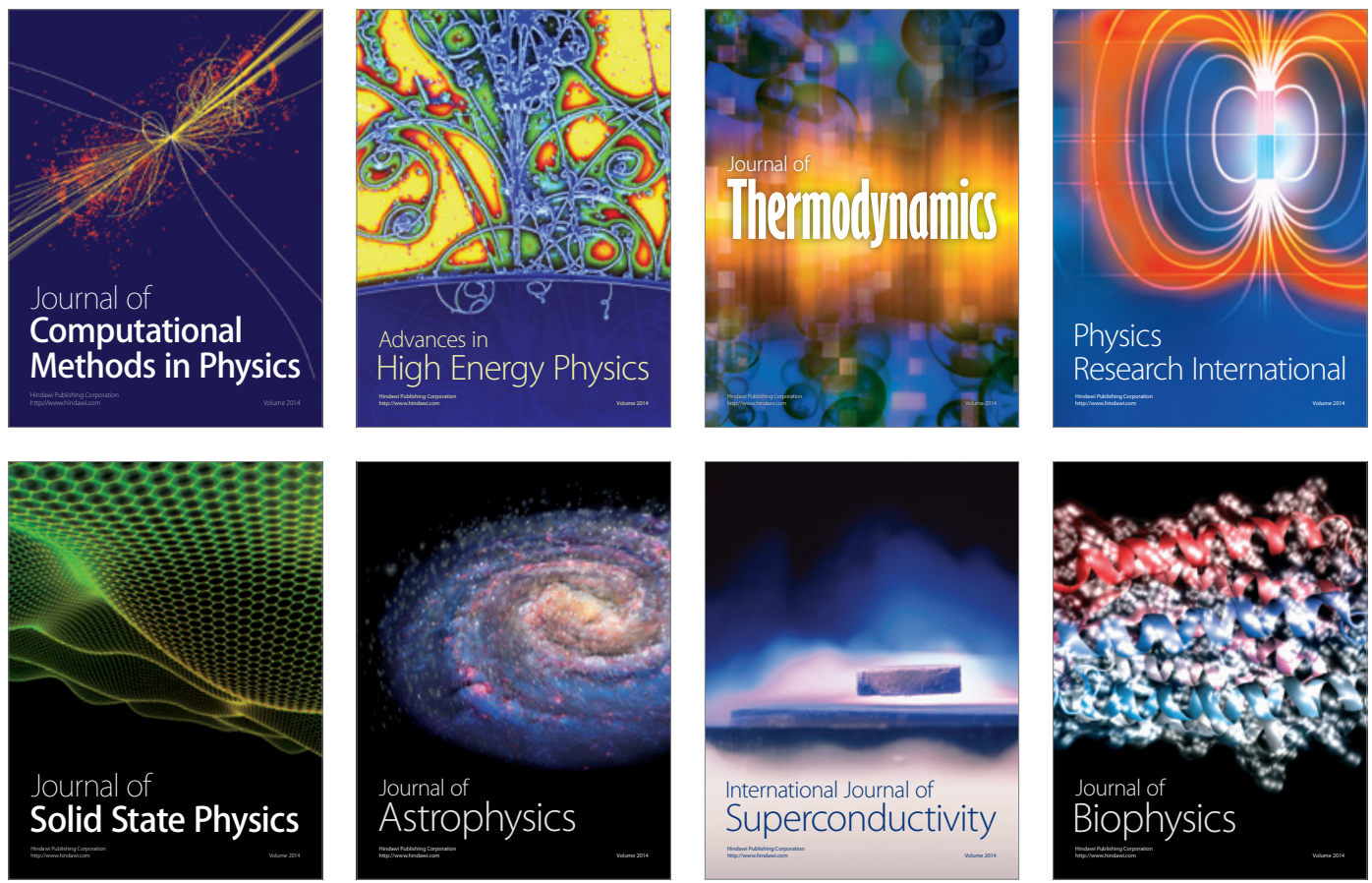
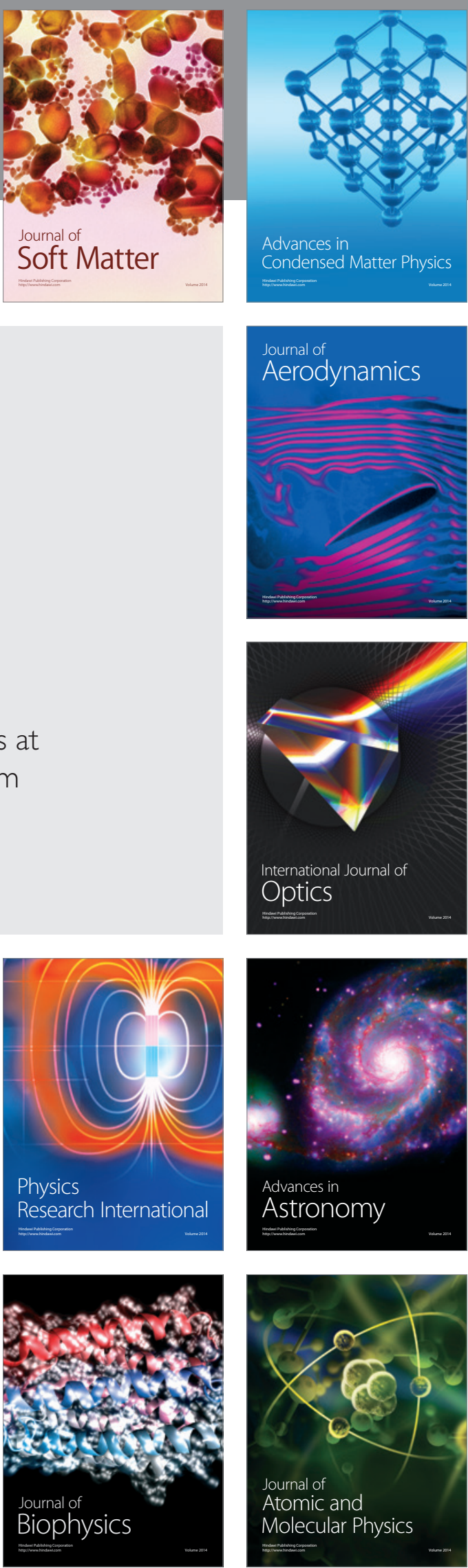